\title{
Laboreal
}

Volume $13 \mathrm{~N}^{\circ} 1$ | 2017

Varia

\section{Organização do trabalho e sofrimento psíquico nas atividades de serviço: o caso dos call centers na Argentina}

Organización del trabajo y sufrimiento psíquico en las actividades de servicio: el caso de los call centers en Argentina

Organisation du travail et souffrance psychique dans les activités de service : le cas des centres d'appels en Argentine

Work organisation and psychic suffering in service activities : the case of Argentine call centres

Patricio Nusshold

Tradutor. Kátia Barbosa Macêdo

\section{(2) OpenEdition}

Journals

Edição electrónica

URL: http://journals.openedition.org/laboreal/798

DOI: $10.4000 /$ laboreal.798

ISSN: 1646-5237

Editora

Universidade do Porto

Refêrencia eletrónica

Patricio Nusshold, "Organização do trabalho e sofrimento psíquico nas atividades de serviço: o caso dos call centers na Argentina », Laboreal [Online], Volume 13 Nº1 | 2017, posto online no dia 01 julho 2017, consultado o 24 setembro 2020. URL : http://journals.openedition.org/laboreal/798 ; DOl : https://doi.org/10.4000/laboreal.798

Este documento foi criado de forma automática no dia 24 setembro 2020.

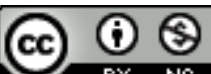

Laboreal está licenciado com uma Licença Creative Commons - Atribuição-NãoComercial 4.0 Internacional. 


\section{Organização do trabalho e sofrimento psíquico nas atividades de serviço: o caso dos call centers na Argentina}

Organización del trabajo y sufrimiento psíquico en las actividades de servicio: el caso de los call centers en Argentina

Organisation du travail et souffrance psychique dans les activités de service : le cas des centres d'appels en Argentine

Work organisation and psychic suffering in service activities : the case of Argentine call centres

\section{Patricio Nusshold}

Tradução : Kátia Barbosa Macêdo

\section{REFERÊNCIA}

Nusshold, P. (2015). Organisation du travail et souffrance psychique dans les activités de service. Le cas des centres d'appels en Argentine. Thèse de doctorat en psychologie du travail, préparée en cotutelle : Universidad de Buenos Aires et École doctorale Abbé Grégoire, Centre de recherche sur le travail et le développement, Conservatoire National des Arts et Métiers, Paris.

\section{NOTA DO EDITOR}

http://dx.doi.org/10.15667/laborealxiii0117pn

Manuscrito recebido em: agosto/2016

Aceite após peritagem: maio/2017 
Júri da tese: Francis Six (Presidente); Christophe Dejours e Mario Poy (Orientadores); Laerte Sznelwar e Eduardo Keegan (Arguentes).

\section{Introdução}

1 A tese de doutoramento aqui apresentada analisa os diversos modelos de intervenção que buscam gerar processos de transformação no mundo do trabalho e suas consequências para a saúde dos trabalhadores. 0 foco do estudo situa-se particularmente no impacto sobre a saúde mental. Este trabalho nasceu a partir de questões relacionadas à prática no terreno da psicodinâmica do trabalho (PDT) e na ergonomia. $\mathrm{O}$ olhar dos especialistas na avaliação dos riscos psicossociais (RPS), a dos ergonomistas e a dos clínicos do trabalho são divergentes, não somente em sua conceção do trabalho, mas também da saúde, e inclusive no que pode significar transformar o trabalho. Apresentam-se suscintamente os objetivos desta investigação, a metodologia escolhida com suas vantagens e seus limites e, por último, os resultados obtidos. Como conclusão, procura-se aprofundar a questão da ação e as possibilidades de transformação das situações de trabalho patogênicas.

\section{Objetivos e metodología}

2 O trabalho de campo da tese, que se concentrou na atividade dos call centers, serviu como ponto de partida para estudar dois grandes temas: (1) as consequências do trabalho nos call centers para a saúde mental; e (2) os diferentes enfoques desta problemática visando sua transformação.

3 Assim, os objetivos desta tese foram:

- Investigar as diferentes formas de cooperação entre os operadores dos call centers;

- Identificar as estratégias de defesa empregadas pelos trabalhadores a partir da lacuna entre o trabalho prescrito e o trabalho real, que devem enfrentar em suas atividades profissionais;

- Comparar a forma de estruturar a organização do trabalho e suas consequências para a saúde dos trabalhadores dos call centers na Argentina, com as de outros países da América Latina e da Europa a partir dos resultados de nosso trabalho de campo.

4 Analisou-se a situação dos call centers na Argentina a partir de uma metodologia que teve vantagens e limites.

5 Houve três momentos diferenciados. Em primeiro lugar, se realizaram visitas ao terreno e uma análise global da atividade utilizando a metodologia da ergonomia, em nove plataformas telefônicas na Argentina, no Brasil e na França. Em seguida, se desenvolveu um trabalho de campo mais profundo, em duas etapas:

- A primeira, seguindo uma metodologia quantitativa, segundo o modelo de avaliação dos riscos psicossociais em dois call centers;

- A segunda, utilizando a metodologia da psicodinâmica do trabalho, partindo da demanda de um coletivo de teleoperadores.

6 A opção de utilizar diferentes metodologias se revelou útil para compreender as abordagens, seus alcances, suas diferenças e seus limites, além de auxiliar a pensar sobre as diversas possibilidades de interação possíveis entre elas. Não obstante, essa estratégia se converteu também em uma restrição. Para poder aprofundar o olhar a 
partir de uma dessas disciplinas, teria sido sem dúvida mais eficaz eleger uma única abordagem.

\section{Principais resultados}

7 A seguir se apresentam os resultados obtidos em cada etapa.

8 Durante os cinco anos de estudo, se realizaram visitas a nove call centers no Brasil, na Argentina e na França. Graças a essas visitas e experiências, foi possível investigar detalhadamente a organização do trabalho nos call centers. Essa atividade económica não parou de crescer e se desenvolver na Argentina. Exerce uma atividade neste contexto, principalmente, uma população de jovens entre 18 e 25 anos, segmento da população que sofre atualmente com o mais alto índice de desemprego.

9 Através das análises globais das atividades, se identificou um modo geral de estruturar a organização do trabalho comum aos diferentes call centers. A distribuição do espaço, as tarefas, os atendimentos, os scripts e as metas de desempenho e produtividade na Argentina, na França e no Brasil apresentaram características similares.

A partir dessa primeira análise geral, as abordagens previamente mencionadas buscaram encontrar respostas ao primeiro eixo dessa investigação, ou seja: a influência do trabalho sobre a saúde mental dos operadores.

Utilizando questionários quantitativos de avaliação dos RPS, se observou que os riscos que representam as mais importantes fontes de estresse para esses coletivos são: as exigências cognitivas no trabalho; a impossibilidade de controlar o tempo e de adaptar seu trabalho; a falta de apoio dos superiores hierárquicos; uma certa fragilidade do grupo; um baixo grau de integração; e por último, a vivência de um trabalho sem sentido.

12 A investigação em PDT, por seu lado, confirmou que, na Argentina, os operadores de call centers experimentam sintomas similares aos das neuroses das telefonistas, juntamente com transtornos músculo-esqueléticos. Os teleoperadores não estão isentos ainda de casos de burnout, depressão e mesmo de suicídio no trabalho, que foram descritos durante a investigação coletiva. A perceção de um trabalho vivenciado como "lixo" é muito próxima da conceção de "trabalho sujo", descrita em outras atividades laborais (Lhuilier, 2005; Molinier, 2009).

13 Além disso, o trabalho de campo permitiu identificar no trabalho de call centers na Argentina a presença de sofrimento ético, vivenciado de diversas formas (Dejours, 1998/2006). A disposição para distorcer a informação e mentir para se adaptar parecem constituir características indispensáveis para realizar o trabalho. As trabalhadoras e os trabalhadores de call centers da Argentina desenvolvem estratégias individuais e coletivas de defesa para manter o seu emprego e ao mesmo tempo não adoecer.

14 A pesquisa permitiu identificar algumas estratégias de defesa similares às reconhecidas por outros investigadores em populações de call centers de outros países. Em particular, encontrou-se também na Argentina defesas coletivas da ordem da infantilização dos trabalhadores, a guerra de clãs e a negação do mal causado aos usuários, tal como descrevem Rolo (2013) em teleoperadores na França, ou Sznelwar, Abrahão e Mascia (2006) no Brasil. Se comprovou ainda a existência de estratégias de defesa que diferem das descritas anteriormente nos call centers. Oferecer um serviço em outro idioma, teria um efeito narcisista para os trabalhadores, pois poderia evidenciar sua capacidade para 
se comunicar em um idioma estrangeiro. Pos sua vez, trabalhar para empresas e usuários estrangeiros mais do que para compatriotas, facilitaria aos operadores a necessidade de se distanciar para realizar as tarefas que reprovam moralmente. Fica como possível eixo a ser desenvolvido em investigações futuras a influência da relação histórica de dominação entre países latino americanos e países ditos "desenvolvidos" no trabalho mediatizado para empresas e usuários estrangeiros.

Outro elemento novo que emergiu da pesquisa de campo foi a presença de mecanismos de defesa que tomam a forma de uma redução no comprometimento com o trabalho. A partir da investigação coletiva em PDT, foi possível identificar uma forma de desobediência à autoridade nos teleoperadores, que pode ir desde transgressões menores até tomar a forma de uma verdadeira desobediência ao regulamento. Essa estratégia de desobediência à autoridade, que encontra alguns pontos em comum com a descrita por Ganem (2012) em trabalhadores hoteleiros na Ilha de Guadalupe, apareceu também nessa população. Diante da falta de reconhecimento, que toma múltiplas formas que vão desde a falta de transparência no pagamento até controles médicos abusivos em caso de doença, pareceria se constituir em outra das principais estratégias para suportar este trabalho com pouca margem de manobra.

Passando agora para o segundo eixo desta tese: que contribuições fazem as diferentes abordagens tendo em vista a ação, a partir dos dados que cada uma proporciona? Se trata de uma questão não somente teórica, relativa a como se geram dados, mas também e sobretudo de uma questão relativa à prática, para os diferentes profissionais: que dados facilitam uma evolução favorável do trabalho?

Risco psicossocial e sofrimento não significam o mesmo. Um dos principais problemas que se enfrenta quando se assimila o conceito de sofrimento a partir da noção de estresse ou de RPS é a negação do lugar que a subjetividade e o sujeito - no sentido da psicanálise - ocupam para a psicopatologia e a psicodinâmica do trabalho. Perde visibilidade, por sua vez, o lugar essencial que ocupam as estratégias de defesa na determinação dos comportamentos e atitudes dos trabalhadores (Dejours, 1980/1990). O modelo dos RPS, baseado principalmente na teoria do estresse, e os modelos de Karasek (1979; Karasek et al., 1998) e de Siegrist et al. (2004; Siegrist, Wege, Pühlhofer, \& Wahrendorf, 2008), busca avaliar, por uma parte, os desencadeantes de estresse e, por outra, a vivência dos trabalhadores em relação à sua insatisfação no trabalho. A partir do modelo dos RPS, se no momento de responder aos questionários, um trabalhador ou um coletivo de trabalhadores proporciona respostas globalmente positivas em relação ao seu trabalho, se pode inferir que o trabalho não possui impacto negativo. Não obstante, como demonstrou a PDT, as estratégias defensivas possuem um lugar central na perceção que os sujeitos possuem da sua situação laboral: que um trabalhador responda positivamente não implica necessariamente que assim seja, pois, a negação, por exemplo, como estratégia de defesa, pode influenciar sua resposta e impedi-lo de identificar os riscos. De fato, se estivesse consciente de certos riscos, é possível que não pudesse continuar trabalhando.

Os questionários utilizados para a avaliação dos RPS puseram em evidência uma contradição entre uma vontade aparente de encontrar soluções, e a falta de questionamento de algumas das causas estruturais dos problemas de saúde mental no trabalho. Diante da tomada de consciência da importância do problema, da relação entre saúde mental dos trabalhadores e a evolução do management, pareceria que uma das únicas abordagens dispostas a enquadrar e gerar as condições para uma verdadeira 
deliberação sobre estas questões é a PDT. A maioria das demais intervenções propostas atualmente, inclusive certos enfoques biomecânicos da ergonomia, parecem cada vez mais influenciadas pelas formas de avaliação quantitativas (seja os TMS ou os RPS) que colocam no centro de suas análises dados quantitativos e não permitem discutir a riqueza do trabalho real e as formas de sofrimento patógeno, de modo tal que se facilitasse a abertura das vias em direção à transformação do trabalho.

\section{4. À guisa de conclusão: mudar o trabalho}

Uma questão que esteve na origem deste trabalho foi colocada por Dejours no Congresso da ODAM [1], em São Paulo, em março de 2008. Ele se perguntava como poderia ser possível que apesar do intenso trabalho que realizamos nas últimas décadas, melhorando indiscutivelmente as condições materiais do trabalho, nos encontrássemos hoje com grande aumento do sofrimento no trabalho, como nunca antes o havia sido. Se ignorava naquele momento que logo se iniciariam as ondas de suicídios ocorridos na França, Japão, Taiwan, China e outros países no mundo, sem nenhum precedente [2].

A que se refere a frase "mudar o trabalho?" Essa pergunta não tem as mesmas respostas para a ergonomia e para a psicodinâmica do trabalho. Para os especialistas na avaliação dos RPS é uma questão ainda mais enigmática, pois as recomendações posteriores à apresentação dos resultados que se realizam a partir desta abordagem, geralmente são bastante vagas, inclusive no documento do colégio de especialistas criado na França a pedido do Ministério do Trabalho (Askenazy et al., 2011).

21 Atualmente a ergonomia, pelo menos na Argentina, tende cada vez mais a medir quantitativamente o trabalho e estandartizar metas, do que a entender o trabalho efetivo e subjetivo de cada um dos coletivos, as consequências sobre a saúde dos trabalhadores e suas estratégias defensivas.

22 A análise da demanda joga, nesse sentido, um papel crucial e inelutável. Trabalhar a partir de uma demanda constitui um ponto partilhado pela ergonomia da atividade e a PDT. Em PDT, quando se consegue implantar uma pesquisa coletiva a partir de uma demanda bem trabalhada, a investigação coletiva se orienta para a ação desde o início do nosso trabalho. Emergem então situações concretas que se encontram na origem do sofrimento desse coletivo de trabalhadores em particular. Situações que os resultados quantitativos não indicam e que podem não ter relação com variáveis ou riscos imaginados a priori pelos questionários.

Que sujeitos e equipes aceitam se questionar sobre seu trabalho? Não é evidente. Tal supõe estarem dispostos a colocar em risco um equilíbrio que levou muito tempo para ser construído, ainda quando o resultado do trabalhar seja para alguns fazer a experiência de diversas formas de sofrimento patogénico. Uma intervenção que permite "fazer como se ..." se abordassem certos problemas sem os obrigar a correr o risco de discutir o trabalho real, supõe não correr o risco de mobilizar as defesas e desestabilizar esse equilíbrio que permite suportar a situação.

Esta investigação teve como intenção evidenciar em que medida a criação de espaços de deliberação é uma astúcia indispensável para restabelecer a relação entre trabalho e prazer, cooperação e, eventualmente, ser fonte de uma forma de emancipação. Para conseguir isso, um trabalho profundo da demanda é indispensável, desde o ponto de 
vista metodológico, ainda que também e sobretudo ético e deontológico. Se um coletivo está disposto a iniciar uma reflexão coletiva para conseguir compreender melhor sua relação com o trabalho, se abre uma via de ação. Somente os coletivos de trabalho que esperam algo de si mesmos, podem pouco a pouco se encarregar de seus próprios problemas. Para isso, é necessário um trabalho prévio de análise da demanda, de construção da investigação, e uma reflexão subsequente que aponte a elaborar uma relação que possa lhes permitir evoluir em seu pensamento. Em PDT se considera que, na medida em que se evolui no pensamento, e somente se o fazem de maneira coletiva, as vias de transformação saudáveis se abrirão, inclusive para modificações dos aspetos materiais, do mobiliário, ou para outros aspetos vinculados à organização do trabalho.

Ao nos limitarmos a uma racionalidade das ciências dos engenheiros, baseada na interface entre homem e máquina, ou a uma determinada ergonomia centrada na produtividade observável, tal supõe fracassar desde o início na possibilidade de gerar transformações no trabalho que se encontrem ao serviço da saúde. Se a deliberação coletiva e o trabalho da demanda desempenham um papel crucial é porque em PDT toda investigação é uma ação que se orienta à emancipação, e somente quem realiza o trabalho pode levar adiante esse processo. Não se pode prescrever, aconselhar, nem indicar. Por isso, considerar a racionalidade moral - prática de toda intervenção, é indispensável. Pelo que foi dito anteriormente, a psicopatologia e a psicodinâmica do trabalho não só aludem à teoria da atividade, mas também à teoria da ação. 0 trabalho não pode ser tomado somente pelas categorias clássicas da produção (poiesis). Implica, por uma parte, categorias teóricas da ação (práxis). Para compreender a dimensão coletiva do trabalho tratando de interpretar a brecha entre coordenação e cooperação, se impõe introduzir a questão da deliberação coletiva (Dejours, 2009). Esta atividade deôntica consiste na construção de normas de trabalho e de valores.

Como pode ser visto, as diferenças entre as disciplinas das que esta tese utilizou, são teóricas e metodológicas, mas também de ordem política. Estas diferenças convocam a subjetividade dos pesquisadores diante do campo que eles abordam durante cada uma de suas investigações. Se trata, então, de um debate entre disciplinas e, ao mesmo tempo, de um debate entre investigadores, sejam eles ergonomistas, clínicos do trabalho ou especialistas em avaliação dos RPS. É o debate em torno da possibilidade de construir um mundo do trabalho - o que busca reforçar a possibilidade de emancipação.

Não se trata de tentar transformar o trabalho simplesmente por transformá-lo. A maioria das transformações vividas no mundo do trabalho ao longo das últimas décadas não fizeram mais que agravar o estado da saúde mental dos trabalhadores. É por isso que resulta indispensável que as diferentes investigações se proponham como objetivo fazer ouvir a voz daqueles que conhecem melhor o trabalho: aqueles que o realizam, aqueles que comprometem dia a dia o seu corpo (Dejours, 2001), sua subjetividade, para preencher a lacuna entre o trabalho prescrito e o trabalho real. Como propõe Dessors (2009), é indispensável enfatizar o terreno, no qual os trabalhadores necessitam e esperam de nós respostas como especialistas do trabalho, mas sobretudo, no que eles esperam de si mesmos. Haverá que pensar naquilo que, em cada contexto, em cada abordagem, permite fazer ouvir sua voz, e facilita que possam se escutar entre eles, sabendo que são, definitivamente, os únicos que conhecem o trabalho real e as dificuldades com que se vêm confrontados diariamente, e portanto, que conhecem as vias possíveis para sua transformação. À medida que possamos fazer ouvir essas vozes, poderemos avançar em direção a uma transformação do trabalho, de nossas disciplinas 
e de nós mesmos como pesquisadores, o que constituirá um aporte, não à alienação e ao isolamento, mas sim à emancipação, inclusive a nossa.

Askenazy, P., Baudelot, C., Brochard, P., Brun, J.P., Cases, C., Davezies, P., Falissard, B., Gallie, D., Gollac, M., Griffiths, A., Grignon, M., Imbernon, E., Leclerc, A., Molinier, P., Niedhammer, I., Parent-Thirion, A., Verger, D., Vézina, M., Volkoff, S., \& Weill-Fassina, A. (2011). Mesurer les facteurs psychosociaux de risque au travail pour les maitriser. Rapport $d u$ Collège d'expertise sur le suivi des risques psychosociaux au travail, faisant suite à la demande du Ministre du travail, de l'emploi et de la santé. París: http://travailemploi.gouv.fr/IMG/pdf/rapport_SRPST_definitif_rectifie_11_05_10.pdf.

Dejours, C. (1980/1990). Trabajo y desgaste mental. Una contribución a la psicopatología del trabajo. Buenos Aires: Área de Estudios e Investigaciones Laborales de la SECYT, CEIL/ CONICET, CREDAL/CNRS, Facultad de Psicología de la UBA, Hvmanitas. Dejours, C. (1998/2006). La banalización de la injusticia social. Buenos Aires : Topía Editora. Dejours, C. (2001). Le corps, d'abord - Corps biologique, corps érotique et sens moral. París: Payot.

Dejours, C. (2009). Travail vivant. Tomes I et II. París : Payot.

Dessors, D. (2009). De l'ergonomie à la psychodynamique du travail. Méthodologie de l'action. París : Érès éditions. Ganem, V. (2012). La désobéissance à l'autorité. L'énigme de la Guadeloupe. París: PUF.

Karasek, R. A. (1979). Job demands, job decision latitude, and mental strain: Implications for job redesign. Administrative Science Quarterly, 24, 285-308. https:// doi.org/10.2307/2392498

Karasek, R., Brisson, C., Kawakami, N., Houtman, I, Bongers, P., Amick, B. (1998). The Job Content Questionnaire (JCQ): An instrument for internationally comparative assessments of psychosocial job characteristics. Journal of Occupational Health Psychology, 3(4), 322-55. https://doi.org/10.1037/1076-8998.3.4.322

Lhuilier, D. (2005). Le " sale boulot ". Travailler, 2, 14, 3-98. https://doi.org/10.3917/trav. 014.0073

Molinier, P. (2009). Des féministes et de leurs femmes de ménage : entre réciprocité du care et souhait de dépersonnalisation. Multitudes, 2, 37-38, 113-121. https://doi.org/ 10.3917/mult.037.0113

Rolo, D. (2013). Contraintes organisationnelles, distorsion de la communication et souffrance éthique. Le cas des centres d'appels téléphoniques. Thèse de doctorat, Conservatoire national des arts et métiers, París. Rolo, D. (2014). Restricciones organizativas, distorsión de la comunicación y sufrimiento ético: el caso de los centros de llamadas. Laboreal, 10 (1), 79-83. http://dx.doi.org/10.15667/laborealx0114dres

Siegrist, J., Starke, D., Chandola, T., Godin, I., Marmot, M., Niedhammer, I., \& Peter, R. (2004). The measurement of effort reward imbalance at work: European comparisons. Social Science \& Medicine, 58, 8, 1483-1499. https://doi.org/10.1016/ S0277-9536(03)00351-4

41 Siegrist, J., Wege, N., Pühlhofer, F., \& Wahrendorf, M. (2008). A short generic measure of work stress in the era of globalisation: effort-reward imbalance. International archives of occupational and environmental health, 82, 1005-1013. https://doi.org/10.1007/ s00420-008-0384-3 
42 Sznelwar, L., Abrahão, J. I., \& Mascia, F. L. (2006). Trabalhar em centrais de atendimento: a busca de sentido em tarefas esvaziadas. Revista Brasileira de Saúde Ocupacional, 31, 114, 97-112. https://doi.org/10.1590/S0303-76572006000200009

\section{NOTAS}

1. ODAM IX: 9th International Symposium on Human Factors in Organizational Design and Management, Guarujá, Brasil, marzo 2008.

2. Suicide et travail: état de la recherche internationale. Travailler 2014/1 ( $\left.n^{\circ} 31\right) .200$ pages. ISSN: $1620-5340$

\section{AUTORES}

\section{PATRICIO NUSSHOLD}

Laboratoire PCPP (Psychologie Clinique, Psychopathologie, Psychanalyse)

Université Paris Descartes

Centre Henri Piéron, 71, av. Edouard Vaillant, 92774 Boulogne Billancourt Cedex France

patricio.nusshold@ast-i.org 